\title{
Marine and continental aerosol effects on the upwelling solar radiation flux in Southern Portugal during the ACE-2 experiment
}

\author{
Claudio Tomasi, Vito Vitale, Angelo Lupi, Alessandra Cacciari, Stefano Marani and Ubaldo Bonafé \\ Istituto di Scienze dell'Atmosfera e del Clima (ISAC), CNR, Bologna, Italy
}

\begin{abstract}
An overall number of 447 spectral series of aerosol optical depth were determined in the 0.4-3.7 $\mu \mathrm{m}$ wavelength range by examining the IR-RAD sun-radiometer measurements carried out at Sagres (Portugal) on six clear-sky days, during the CLEARCOLUMN (ACE-2) experiment in June and July 1997. These spectral series were then analysed with the King inversion method to define the size-distribution curves of columnar aerosol particle total number and volume, assuming values of both real and imaginary parts of the particulate refractive index obtained on the six days by combining our measurements with simultaneous sky-brightness measurements taken by the Leipzig University group. For these results, we then calculated the daily time-patterns of the average single scattering albedo of the columnar aerosols, finding instantaneous values ranging between 0.70 and 0.96 on those days, with daily mean values varying from 0.83 to 0.95 . Furthermore, for each spectral series of aerosol optical depth, we determined the instantaneous change $\Delta F \uparrow$ induced by the columnar aerosols on the upwelling solar radiation flux leaving the atmosphere, over oceanic areas presenting low surface albedo. The 24-h average values of $\Delta F \uparrow$ obtained on the six days were found to increase as a function of the daily mean value of aerosol optical depth at the $0.55 \mu \mathrm{m}$ wavelength, following relationship curves whose positive slope coefficients decrease gradually with the single scattering albedo of the columnar aerosols. The said curves can be used to achieve reliable estimates of change $\Delta F \uparrow$ directly from daily ground-based multispectral measurements of aerosol optical depth and skybrightness at different angular distances from the Sun.
\end{abstract}

Key words aerosol optical depth-aerosol particle size-distributions - aerosol radiative properties - direct aerosol radiative forcing

\section{Introduction}

It is well known that airborne aerosols act on the Earth's climatic system in two ways, directly through scattering and absorption of both solar and terrestrial radiation, and indirectly by

Mailing address: Dr. Claudio Tomasi, Istituto di Scienze dell'Atmosfera e del Clima (ISAC), CNR, Via Gobetti 101, 40128 Bologna (Italy); e-mail: c.tomasi@isac.cnr.it modifying the optical properties and lifetime of clouds (Charlson et al., 1991). The uncertainties in estimating direct aerosol-induced forcing arise from the limited information on the spatial and temporal distribution of aerosol particles and on their optical properties. In fact, while global three-dimensional distribution data of sulphate aerosols are currently available (Langner and Rodhe, 1991), the global scale distribution features of the other aerosol components are only scantily known. In addition, the close dependence of the optical properties on the size-distribution characteristics of airborne particles and their chemical composition makes it difficult to define simple and realistic relationships between direct 
aerosol-induced forcing and columnar particulate content parameters. For these reasons, several regional experiments have been carried out over recent years in different areas of the planet to study the direct effects produced by aerosols in scattering and absorbing the incoming solar radiation: among them, the most important in oceanic areas have been ASTEX/MAGE in the Eastern Atlantic (Huebert et al., 1996), ACE-1 in the Southern Pacific (Bates et al., 1998), INDOEX in the Indian Ocean (Jayaraman et al., 1998), TARFOX in the eastern coastal region of U.S.A. (Russell et al., 1999a), and ACE-2 in the Northern Atlantic (Raes et al., 2000).

During the ACE-2 experiment, our group participated in the CLEARCOLUMN project, along with other groups from the U.S.A., Germany, France, Portugal, Sweden and the Netherlands (Russell and Heintzenberg, 2000). The CLEARCOLUMN campaign took place in June/July 1997 in Portugal, the Canary Islands and the surrounding regions of the Eastern Atlantic Ocean. Our specific role was to perform routine measurements of direct solar irradiance at Sagres $\left(37^{\circ} 01^{\prime} \mathrm{N}, 8^{\circ} 57^{\prime} \mathrm{W}\right.$; $50 \mathrm{~m}$ a.m.s.l.) on the Atlantic coast of Southern Portugal and at the nearby mountain stations of Monchique $\left(37^{\circ} 19^{\prime} \mathrm{N}, 8^{\circ} 34^{\prime} \mathrm{W} ; 500 \mathrm{~m}\right.$ a.m.s.l.) and Mt. Foia $\left(37^{\circ} 19^{\prime} \mathrm{N}, 8^{\circ} 36^{\prime} \mathrm{W}\right.$; $920 \mathrm{~m}$ a.m.s.l.), with the aim of obtaining precise measurements of Aerosol Optical Depth (AOD) at several visible and infrared wavelengths on numerous days of the campaign. The mountain measurements were performed using portable sun-photometers, providing direct solar radiation output voltages at 11 and 13 window-wavelengths, respectively, in the 0.32-1.05 $\mu \mathrm{m}$ spectral range. The Sagres measurements were taken with the IR-RAD sun radiometer, designed and manufactured by us at the ISAC Institute, which is equipped with 13 narrow passband interference filters centered within the main windows of the solar spectrum from 0.401 to $3.676 \mu \mathrm{m}$. We collected large data-sets on 21 completely clear-sky days and other 6 partially cloudy days, for an overall number of more than 2100 spectral series of direct solar irradiance output voltages (Vitale et al., 2000a). Covering so wide a spectral interval, the evaluations of AOD obtained from the IR-RAD measurements were found to be particularly suitable for analysis by means of retrieval procedures to determine the sizedistribution curves of the columnar aerosol particle polydispersions and obtain useful information on the refractive index of particulate matter and other radiative properties of airborne aerosols.

This paper briefly presents:

i) the procedure followed to determine the AOD spectral series at various times on six clearsky days;

ii) the inversion procedure adopted to infer the columnar particle number and the volume distribution curves as a function of radius, determining the radiative properties of the columnar aerosol particles in terms of the complex refractive index of particulate matter, and

iii) the calculations of the changes in the upwelling solar radiation flux at the atmospheric top-level produced over an oceanic region by columnar particle polydispersions of marine, continental and mixed origins, as observed on six selected days of the CLEARCOLUMN campaign.

\section{The spectral AOD measurements}

The optical and electronic characteristics of the IR-RAD sun-radiometer are described in detail by Vitale et al. (2000a), along with the procedures followed to attain an accurate calibration of the instrument at the 13 selected window-wavelengths. In particular, the instrument is equipped with a collimator tube containing a set of circular diaphragms defining a field of view of $1^{\circ} 16^{\prime}$ diameter at all wavelengths. The use of such a limited field of view prevents important errors due to the sky diffuse radiation entering the radiometer and reaching the thermopyle employed as sensor. Thus, we assumed that the output voltages were only due to direct solar irradiance on all the measurement days presenting relatively high atmospheric transparency conditions, according to the results found by Tomasi et al. (1999) for different atmospheric scattering models. All the optical and electronic components are housed in a thermostated box which is maintained at the internal temperature of $15^{\circ} \mathrm{C}$ by a set 
of four thermoelectric (Peltier) heat pumps. This device enables us to minimize the errors caused by temperature drift effects on the filter transmission curves and/or thermal instability of the thermopyle, whose signals are regularly checked by means of a thermostated chopper disk providing the zero signals.

Precise values of the calibration constants of a sun-radiometer are needed in analyzing the sun-radiometer output voltages to determine the spectral values of AOD. In fact, the calibration constants are the spectral signals which would be given by the instrument if used outside the atmosphere, when the Earth-Sun distance assumes the yearly mean value. They were first determined during an intercomparison campaign held at the Schneefernerhaus Observatory (2665 m a.m.s.l.) on the Zugspitze (Germany) in October 1996 (Tomasi et al., 1998), and subsequently checked at Sagres on the final days of the campaign (Vitale et al., 2000a), in both cases by applying the Langley plot method to the field measurements. All the spectral series of IR-RAD signals were then examined in terms of the Bouguer-Lambert-Beer law to determine the values of total atmospheric optical thickness at the 13 window-wavelengths. The values were subsequently corrected for the Rayleigh scattering contribution and the terms due to absorption by water vapour, ozone, nitrogen dioxide and other minor gases, thus obtaining the spectral series of aerosol optical depth $\delta(\lambda)$ at the window-wavelengths (Vitale et al., 2000a). Three examples of spectral series of $\delta(\lambda)$ are shown in fig. 1 , for different times on three measurement days. In order to assess the variability of the wavelength dependence features of $\delta(\lambda)$, we examined all the IR-RAD spectral series of $\delta(\lambda)$ taken within the 0.401 $1.025 \mu \mathrm{m}$ wavelength range in terms of the well-



Fig. 1. Spectral series of aerosol optical depth $\delta(\lambda)$ determined from the IR-RAD sun-photometer measurements carried out on June 19, 1997, at 09:52 GMT (circles), July 5, 1997, at 17:47 GMT (triangles), and July 20, 1997, at 11:23 GMT (squares). The corresponding Ångström (1964) best-fit lines determined in the 0.401-1.025 $\mu \mathrm{m}$ spectral range are also drawn (dashed lines), together with the corresponding best-fit values of atmospheric turbidity parameters $\alpha$ and $\beta$. 
known Ångström (1964) formula to determine the best-fit values of the atmospheric turbidity parameters $\alpha$ and $\beta$. The results obtained for the three above examples are also reported in fig. 1, showing that considerably higher values of $\delta(\lambda)$ were found on July 20, 1997, compared to those of the two other examples of June 19 and July 5, 1997. The spectral features of $\delta(\lambda)$ relative to the two examples of July appear to be quite smooth, very closely following the Ångström (1964) relationship. The example of June 19, 1997 presents lower values of AOD, with a well-defined minimum at about $0.7 \mu \mathrm{m}$ wavelength. Such spectral features are very similar to those observed by Quenzel (1970) in spectral series of AOD derived from direct solar radiation measurements taken in the tropical Atlantic Ocean, where they were ascribed to the presence of very peaked modes of marine aerosols in the columnar size-distribution curve, appropriately represented in terms of narrow lognormal curves with mean radii ranging between 0.5 and $0.9 \mu \mathrm{m}$.

The three examples presented above suggest that important variations in the spectral dependence features of AOD may take place from one day to another, indicating that marked changes occur in the columnar particle sizedistribution curve, as well as in the refractive index of particulate matter. More generally, all the radiative properties of aerosol particles strongly depend on both size-distribution curve and refractive index and, therefore, are closely related to the origin of the particulate matter. Thus, when studying the aerosol radiative effects, it is of crucial importance to establish the particulate origin. This can be more confidently achieved, for instance, by sampling the particulate matter and defining the backward Lagrangian trajectories of the air masses passing over the measurement station, as was systematically done during the CLEARCOLUMN campaign at Sagres, to ascertain the origin of aerosol particles at the various altitudes and the climatic effects produced by airborne aerosols. In fact, the aerosols of marine origin usually scatter very strongly and very weakly absorb the incoming solar radiation, while particles of continental (polluted) origin or mixed composition may cause very intense absorption effects if they contain important fractions of soot. Thus, marine aerosol particles suspended over a sea surface characterised by low albedo are expected to induce an increase in the outgoing flux of solar radiation at the top of the atmosphere; this implies a corresponding increase in the local albedo of the surfaceatmosphere system and, consequently, a cooling effect in the energy budget. Conversely, aerosols containing a relatively high fraction of soot matter are expected to cause weaker cooling effects or effects of opposite sign, giving rise to a decrease in the local albedo (Paltridge and Platt, 1976).

\section{Application of the inversion method to the AOD spectral series}

The main purpose of the present work is to evaluate the variations caused by marine and continental aerosols of different composition in the upwelling solar radiation flux at the atmospheric top-level, when these particles are suspended over a sea surface. To provide evidence of the large differences between the radiative effects caused by pure marine particle polydispersions and those due to continental aerosols mainly generated by anthropic activities, we decided to examine a limited number of daily data-sets collected during the CLEARCOLUMN campaign; they were selected so as to represent a variety of columnar aerosol contents presenting different aerosol composition cases, gradually passing from the extreme case of a nearly entirely marine aerosol population to the opposite case of particle populations mainly consisting of polluted continental aerosols originating from industrial and highly populated areas of Europe and, consequently, containing only a negligible fraction of maritime particulate matter. Hence, we selected six measurement days to determine the columnar size-distribution features, the radiative properties of particulate matter and the aerosolinduced effects on the outgoing solar radiation. In particular, we examined each spectral series of $\delta(\lambda)$ to determine the Ångström (1964) best-fit values of parameters $\alpha$ and $\beta$ : the latter in practice gives the measure of the aerosol optical depth at $1 \mu \mathrm{m}$ wavelength, while $\alpha$ is determined as the slope coefficient of the best-fit line. Parameter $\alpha$ closely depends on the shape-parameters of 
the aerosol size-distribution curve (especially on those characterising the size range of the large and giant particles, which are known to cause the most important extinction effects) and, to a lesser extent, on the complex refractive index of particulate matter (Curcio, 1961; Tomasi et al., 1983). Therefore, $\alpha$ provides a reliable evaluation of the relative contribution of the large and giant particles to the overall aerosol extinction in the atmospheric column.

The six selected days were:

1) June 19, 1997, when the analysis of the backward trajectories drawn during the previous five days showed that the air masses arrived from the Northern Atlantic with prevailing directions from the NE quadrant at all the tropospheric levels. This indicates that the columnar aerosol particle polydispersion mainly consisted of marine particulate matter. The daily mean values of $\alpha$ and $\beta$ were found to be equal to $0.63 \pm 0.37$ and to $0.06 \pm 0.04$, respectively. Therefore, we considered this day as particularly appropriate to represent a totally marine aerosol case.

2) June 23, 1997, when the analysis of the backward trajectories showed that the air masses flowing at altitudes lower than $3 \mathrm{~km}$ arrived from the north after circulating over the British Isles, the Bay of Biscay and Portugal, while those at the upper levels came directly from the Atlantic Ocean. Therefore, the columnar particle polydispersions observed on this day at Sagres were assumed to consist of mixed aerosols with a prevailing content of marine particles. This assumption fully agrees with the daily mean value of parameter $\alpha$ found equal to $0.15 \pm 0.08$ and with that of $\beta$ equal to $0.08 \pm 0.03$.

3) July 5, 1997, when the backward trajectories drawn at levels below $4 \mathrm{~km}$ indicated that the air masses arrived from the Northern Atlantic but circulated over Portugal and the western regions of Spain during the previous thirty hours. Therefore, the columnar particle polydispersions were presumably composed of mixed aerosols, with prevailing radiative effects due to marine aerosols, the daily mean values of $\alpha$ and $\beta$ being evaluated as equal to $0.35 \pm 0.23$ and $0.05 \pm 0.02$, respectively.

4) July 7, 1997, when the air masses circulated for a long time period within the ground layer of about $3 \mathrm{~km}$ depth over the Iberian Penin- sula, the western part of the Mediterranean and the Atlas mountain region, while only those at levels higher than $5 \mathrm{~km}$ came from the Atlantic Ocean. Therefore, the columnar aerosol particle polydispersions were estimated to be mostly composed of continental-anthropic particulate matter, with the presence of a very low fraction of marine aerosols. The daily mean values of $\alpha$ and $\beta$ were found equal to $0.84 \pm 0.11$ and $0.09 \pm 0.02$, respectively.

5) July 18, 1997, when the air masses suspended within the first $4 \mathrm{~km}$ of the atmosphere had previously circulated for at least five days over the European regions and mainly over the Iberian Peninsula and the western part of the Mediterranean, while only those at levels higher than $5 \mathrm{~km}$ clearly appeared to be of oceanic origin. Thus, the aerosol particle loading in the vertical column was evaluated to have a mixed composition, with a prevailing fraction of continental-anthropic particulate matter and a smaller part of marine aerosols. The daily mean values of parameters $\alpha$ and $\beta$ were found to be equal to $1.04 \pm 0.10$ and to $0.14 \pm 0.03$, respectively.

6) July 20, 1997, when the air masses arriving above the Sagres station at all levels circulated at length over the Bay of Biscay and the coastal regions of France before reaching the Iberian Peninsula. Thus, the columnar aerosol particle polydispersions were all considered to be predominantly composed of polluted substances of anthropic origin. This assumption agrees very well with daily mean values of $\alpha$ and $\beta$, found to be equal to $0.88 \pm 0.05$ and $0.15 \pm 0.02$, respectively.

In order to examine the different spectral features presented by the columnar aerosols on the above-selected six days for determining the corresponding particle size-distributions, we analysed the 447 spectral series of $\delta(\lambda)$ measured on those days using the King (1982) inverse method for inferring the size-distribution curves of the columnar total particle number $N$ within the $0.07-10 \mu \mathrm{m}$ radius range, according to the procedure followed by Vitale et al. (2000b). In order to apply this inversion procedure, we needed to use realistic values of both real part $n$ and imaginary part $k$ of the particulate matter refractive index. For this purpose, we 
determined the daily mean values of these two optical quantities by taking into account the results obtained by Vitale et al. (2000a) from the analysis of the AOD spectral series, as well as the daily estimates of both $n$ and $k$ found at the Sagres and Mt. Foia stations on the same days by the Leipzig University group (von Hoyningen-Huene, private communication). The latter estimates were obtained following the procedure described by von Hoyningen-Huene et al. (1999) and were based on the combined examination of simultaneous measurements of AOD spectral series, solar radiation fluxes and sky-brightness, these last measurements being taken in almucantar for various angular distances from the Sun. This analysis provided the following daily mean values of the real part $n$ and imaginary part $k$ of the particulate refractive index:

i) $n=1.43$ and $k=0.0037$, on June 19,1997 , in the presence of pure marine aerosol polydispersions;

ii) $n=1.47$ and $k=0.0067$ on June 23 and July 5,1997 , in the presence of mixed aerosols with predominant contents of maritime particles; iii) $n=1.48$ and $k=0.0122$ on July 18,1997 , when the predominant content in the atmospheric column was given by continental particles and a smaller fraction of marine aerosols was present at higher altitudes and

iv) $n=1.50$ and $k=0.0138$ on July 7 and 20, 1997, both presenting columnar contents of prevailing continental-anthropic (polluted) aerosols.

Using these values of $n$ and $k$, we applied the King (1982) inversion method to all the spectral series of AOD measured on the six days selected above, inferring from them the size-distribution curves of the columnar total particle number $N$ in the $0.07-10 \mu \mathrm{m}$ radius range, from which we also calculated the size-distribution curves of the columnar total particle volume $V$. Figure 2 shows the size-distribution curves of quantities $N$ and $V$, as found for the three AOD spectral series shown in fig. 1. The three number size-distribution curves exhibit clear bimodal features, characterised by the presence of pronounced modes of large and giant particles in the $0.3-3 \mu \mathrm{m}$ radius range, which are expected to cause the most important extinction features at the visible and near-infrared

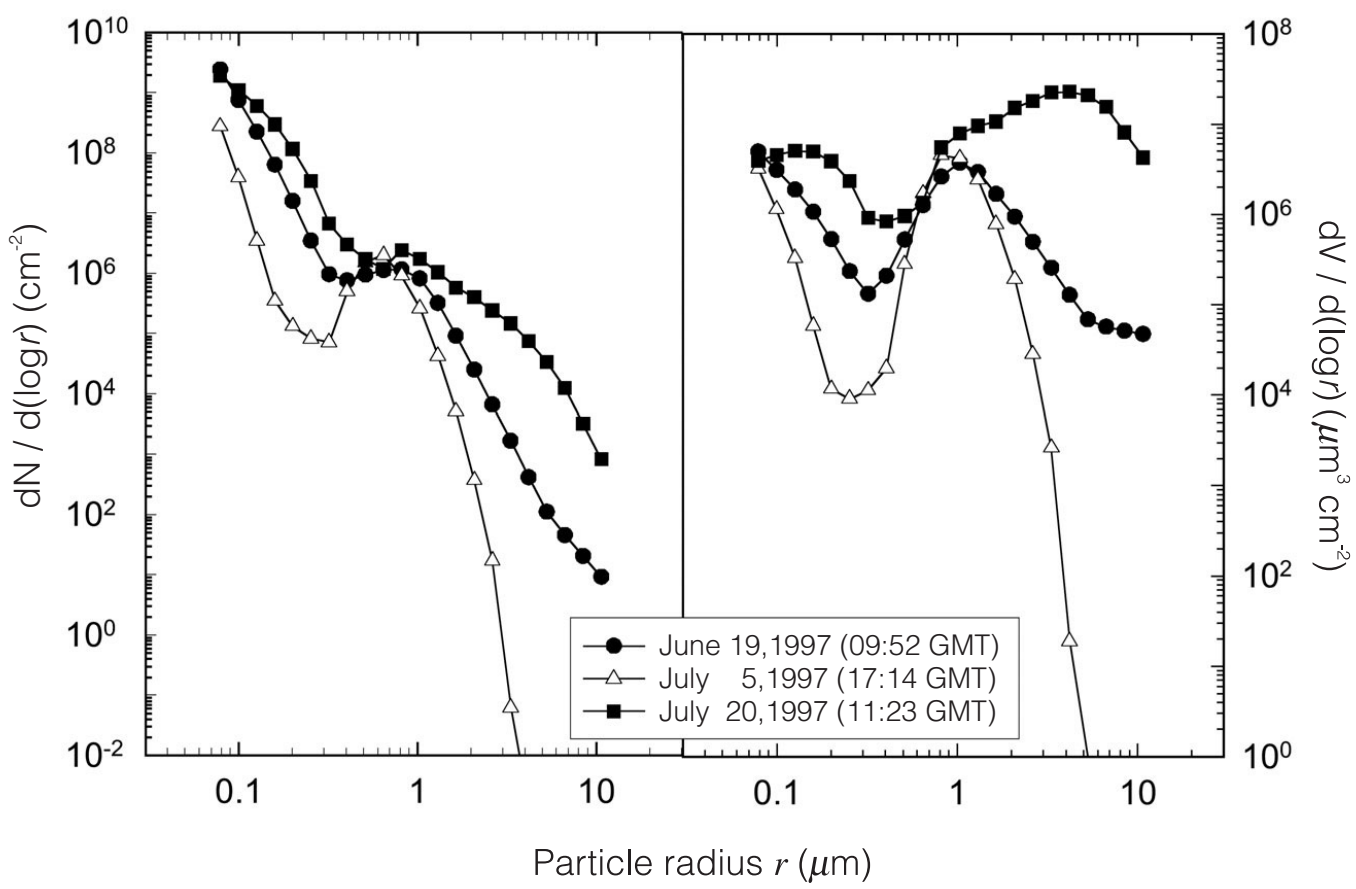

Fig. 2. Size-distribution curves of the columnar total particle number $N(l e f t)$ and columnar total particle volume $V(r i g h t)$, found by analysing the three spectral series shown in fig. 1 with the King (1982) inverse method. 
wavelengths. Correspondingly, the three volume size-distribution curves show that such modes of large and giant particles provide the predominant contribution to the columnar aerosol volume, since they all exhibit high values throughout the radius range from 0.3 to $10 \mu \mathrm{m}$.

\section{Calculation of the single scattering albedo for marine, mixed and continental aerosols}

The determination of the radiative properties of a columnar aerosol polydispersion requires a knowledge not only of the size-distribution curve of the columnar total particle number $N$ but also of the dependence curves of the refractive index parts $n$ and $k$ on wavelength. Therefore, we determined the spectral functions $n(\lambda)$ and $k(\lambda)$ for each day, representing each columnar aerosol polydispersion as a linear combination of three of the four aerosol basic components defined in the 6S computer code, i.e. oceanic, water-soluble and soot components (Vermote et al., 1997). This was carried out following the procedure proposed by Vitale et al. (2000b), obtaining spectral curves of $n(\lambda)$ and $k(\lambda)$ yielding average values of $n$ and $k$ over the 0.4-3.7 $\mu \mathrm{m}$ wavelength range equal to those defined above on the six days and used in applying the retrieval procedure to the AOD spectral series. The choice of the linear combination of the three $6 \mathrm{~S}$ basic aerosol components and the definition of the retrieved columnar size-distribution curves of $N$ are both crucial for determining the radiative properties of the particle polydispersions. This is because the radiative parameters of each particle, like the single scattering albedo, the phase function and the asymmetry factor, all closely depend on the spectral features of both real and imaginary parts of particulate refractive index, as predicted by Mie theory (Deirmendjian, 1969). Thus, the monochromatic single scattering albedo $\omega(\lambda)$ of each aerosol particle polydispersion is given by the integral of the single scattering albedo of a spherical particle of radius $r$ multiplied by the columnar size-distribution curve $n(r)=\mathrm{d} N / \mathrm{d} r$ over the whole particle radius range. Parameter $\omega(\lambda)$ provides the fraction of the solar radiation undergoing aerosol extinction which is subject to scattering, the residual percentage being lost through aerosol absorption. Therefore, we calculated $\omega(\lambda)$ at 10 significant wavelengths in the 0.4-3.75 $\mu \mathrm{m}$ range for each spectral series of AOD, using the spectral curves of $n(\lambda)$ and $k(\lambda)$ determined above for the corresponding day and the retrieved size distribution curve $n(r)$ as weight function. We then calculated for each AOD spectral series the weighted average value $\omega$ of the single scattering albedo of the corresponding columnar aerosol polydispersion, using as weight function the spectral curve of the solar radiation reaching the ground, as calculated with the $6 \mathrm{~S}$ computer code for a standard midlatitude summer atmosphere model (Anderson et al., 1986), where we assumed that the AOD spectral series is the one measured at that time and the solar zenith angle is equal to $60^{\circ}$. Figure $3 a, b$ shows the time-patterns of aerosol optical depth $\delta(550 \mathrm{~nm})$ obtained from the IR-RAD measurements carried out on the six selected days and the daily time-patterns of the average single scattering albedo $\omega$. The time-patterns of $\delta(550 \mathrm{~nm})$ appear in general to slowly decrease during the morning, presumably as a result of the gradual decrease in the marine breezes moving from the ocean toward the inland areas, and the simultaneous reduction in the large particle sizes due to the decrease in air relative humidity caused by the solar heating. During the afternoon, a slow increase of $\delta(550 \mathrm{~nm})$ was often observed, generally associated with variations in the local circulation favouring the arrival of continental particulate matter from the more polluted region of Lisbon or from other urban areas of the Iberian Peninsula.

With regard to the time-variations in $\omega$, it can be noticed in fig. 3b that on June 19, 1997, characterised by the large presence of marine aerosols, this parameter was found to present appreciably higher values than those obtained for June 23 and July 5, when mixed aerosols were present with predominant fractions of marine particles, and for July 18 in the presence of continental aerosols and a less important fraction of marine particles. In fact, a daily mean value $\varpi$ of the single scattering albedo equal to 0.95 was found on June 19, while values of $\varpi$ equal to $0.87,0.86$ and 0.89 were determined on the three above-mentioned days, respectively. A lower value of $\varpi=0.83$ was found on July 7 
and 20,1997, both days being characterised by the presence of optically prevailing contents of continental aerosols. These evaluations of $\omega$ are very important in improving our understanding of the role played by aerosols in modifying the radiative balance of the atmosphere through a greater or lesser intense scattering of the incoming solar radiation.

The above evaluations of $\omega$ were obtained by using the columnar aerosol size-distribution curves retrieved from the IR-RAD measurements of aerosol optical depth employing fixed values of $n$ and $k$ and assuming both refractive index parts not to vary with time throughout the daily period. Our assumption of fixed values of $n$ and $k$ was required since the Leipzig University group followed the von Hoyningen-Huene et al. (1999) procedure, providing us with only mean daily values of the refractive index parts (private communication). In reality, both $n$ and $k$ are expected to vary frequently with time as a consequence of transport and/or physical processes, such as the evaporation of haze droplets, formation of new particles through gas-toparticle conversion and growth of aerosols by coagulation or condensation. Together, such processes give rise to appreciable modifications in the shape of the columnar aerosol sizedistribution curve, which generally presents multimodal features like those shown in fig. 2. Thus, the use of fixed values of $n$ and $k$ in the King (1982) inversion procedure led us to obtain retrieved size-distribution curves appreciably different from those which would be found using the true values of $n$ and $k$. In order to give a measure of how large could be the variations in the calculations of $\omega$ arising from the above assumptions, we estimated that the diurnal variations in $n$ and $k$ occurring during the day, for anticyclonic conditions and weak transport of particulate matter, as in the cases of July 5, 7 and 20, 1997, can be reasonably assumed to be limited within \pm 0.02 for the real part $n$, and within $\pm 50 \%$ for the imaginary part $k$. Thus, calculations of $\omega$ were made for the above three days, first by changing the values of $n$ and using stable values of $k$, and subsequently for stable values of $n$ and different values of $k$, determining correspondingly the columnar aerosol sizedistribution curves through the King (1982) retrieval procedure. The results indicate that $\omega$ can vary by $\pm 6.0 \%$ on July 5 for $n$ changing from 1.47 to $1.47 \pm 0.02$, and by no more than $\pm 3.5 \%$ on July 7 and July 20 for $n$ varying from 1.50 to $1.50 \pm 0.02$, the values of $k$ remaining unchanged. Conversely, for fixed values of $n$ on the three days, $\omega$ was found to vary by no more than $\pm 10 \%$ on July 5 for values of $k=0.0067 \pm$ \pm 0.0033 , and by about $\pm 8 \%$ on the other two days for values of $k=0.0138 \pm 0.0069$. These and other more extended calculations indicate that the assumption of fixed values of $n$ and $k$ during the whole day can imply overall relative errors in the estimates of $\omega$ of no more than $\pm 30 \%$ for anticyclonic conditions favouring only weak processes of particulate matter transport.

\section{Calculation of the diurnal changes in the upwelling solar radiation flux}

The radiative effects caused by airborne particles on solar radiation can be properly represented in terms of both intensity and sign of the aerosol-induced change $\Delta F \uparrow$ in the upwelling solar radiation flux $F \uparrow$ leaving the atmosphere. Calculations of change $\Delta F \uparrow$ were performed by us for all the AOD spectral series determined from the IR-RAD measurements taken on the six selected clear-sky days. In these calculations, we followed the procedure proposed by Vitale et al. (2000b), which employs the 6S computer code (Vermote et al., 1997) to calculate the upwelling flux of solar radiation at the top-level of the atmosphere, over the $2 \pi$ solid angle. This was carried out by calculating the flux components at numerous different zenith and azimuth angles and integrating them over the hemisphere. The calculations of $F \uparrow$ were performed for each IR-RAD spectral series of AOD assuming that:

i) The vertical profile of temperature and relative humidity is that determined at each measurement-time by interpolation in time between the profiles obtained from the radiosounding measurements taken on the same day at the Sagres station and San Teotonio station $\left(37^{\circ} 33^{\prime} \mathrm{N}\right.$, $8^{\circ} 43^{\prime} \mathrm{W} ; 119 \mathrm{~m}$ a.m.s.1.), $60 \mathrm{~km}$ NNE of Sagres, for an overall number of 4 to 8 radiosonde launches per day (Tomasi et al., 2000). 
ii) The vertical contents of $\mathrm{O}_{3}, \mathrm{CO}_{2}, \mathrm{O}_{2}$ and other minor gases are those assumed in the standard mid-latitude summer atmosphere model defined by Anderson et al. (1986).

iii) The apparent solar zenith angle is that corresponding to the median IR-RAD measurement time.

iv) The columnar particle size-distribution curve is that retrieved from the IR-RAD spectral series of AOD.

v) The spectral curves of particulate refractive index parts $n(\lambda)$ and $k(\lambda)$ are those determined above on the various days.

vi) The spectral reflectance curve of the surface is that defined by the $6 \mathrm{~S}$ computer code for a clear water surface, which simulates with a good approximation the reflectance characteristics of the sea surface for calm wind conditions.

Thereupon, we calculated the ougoing flux $F_{0} \uparrow$ for the same atmospheric model configuration, in which the columnar aerosol mass content was instead assumed to be null. The difference $\Delta F \uparrow$ between the value of flux $F \uparrow$ with aerosols and that of $F_{0} \uparrow$ without aerosols was considered to be a realistic estimate of the change instantaneously produced by the airborne aerosols at the measurement time (Hänel et al., 1999). The time-patterns of $\Delta F \uparrow$ obtained on the six days are shown in fig. 4a. They indicate that the highest values of $\Delta F \uparrow$ (in general greater than $10 \mathrm{Wm}^{-2}$ ) were achieved on July 18 and 20, 1997, that is, on days presenting values of AOD higher than 0.20 and atmospheric particle loadings predominantly consisting of continental aerosols, although with different values of the columnar aerosol single scattering albedo: it was estimated to assume values ranging mainly between 0.85 and 0.90 on July 18 and between 0.75 and 0.85 on July 20 , as shown in fig. $3 \mathrm{~b}$. Values of $\Delta F \uparrow$ mainly ranging between 5 and $10 \mathrm{Wm}^{-2}$ were obtained on the three days characterised by the presence of mixed aerosol polydispersions, when values

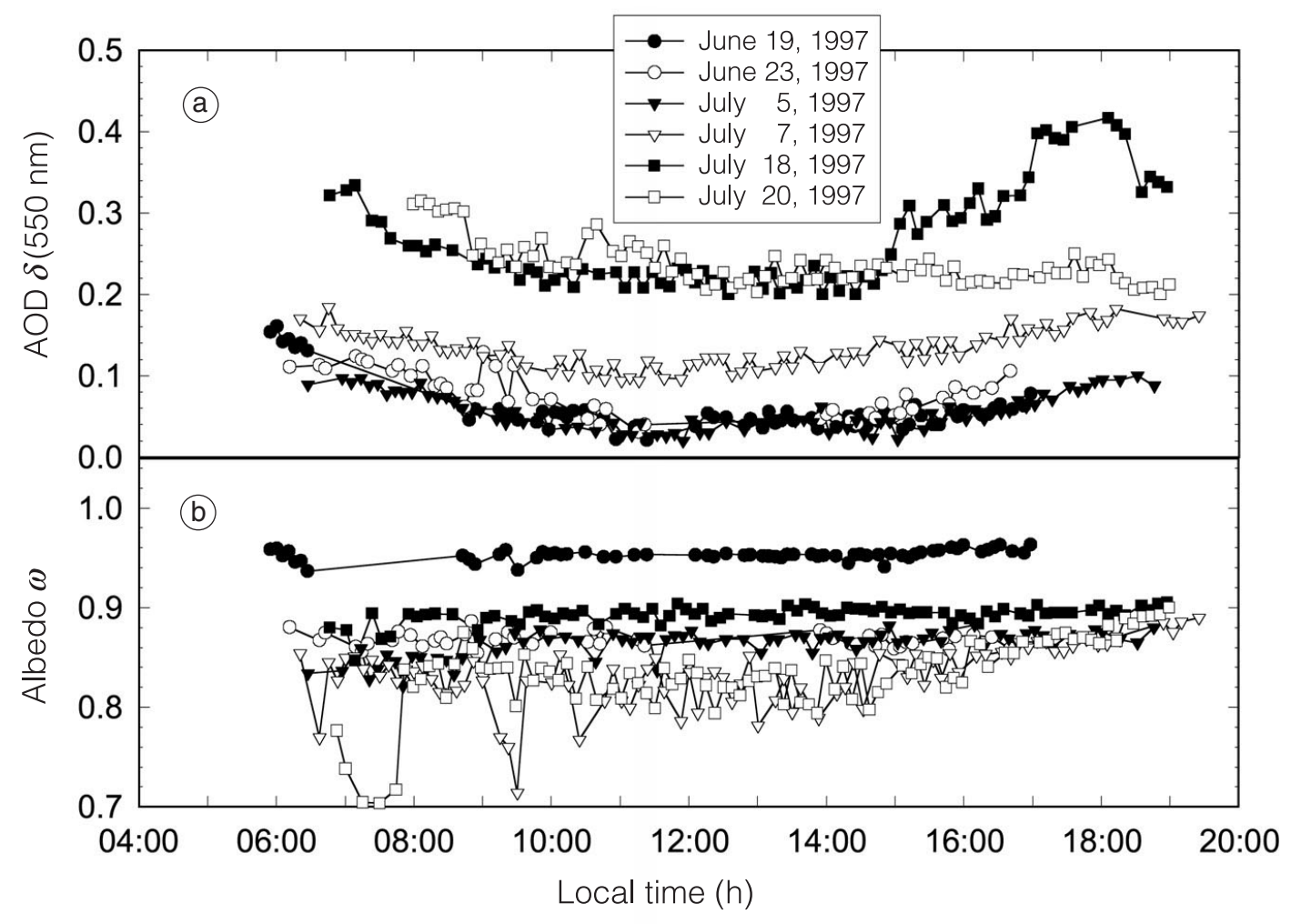

Fig. 3a,b. a) Time-patterns of aerosol optical depth $\delta(550 \mathrm{~nm})$ measured on the six selected days; b) timepatterns of the average single scattering albedo $\omega$ of the columnar aerosols, calculated on the same six days for marine aerosols (June 19), mixed aerosol polydispersions (June 23, July 5 and July 18), and continental (polluted) aerosols (July 7 and 20, 1997). 


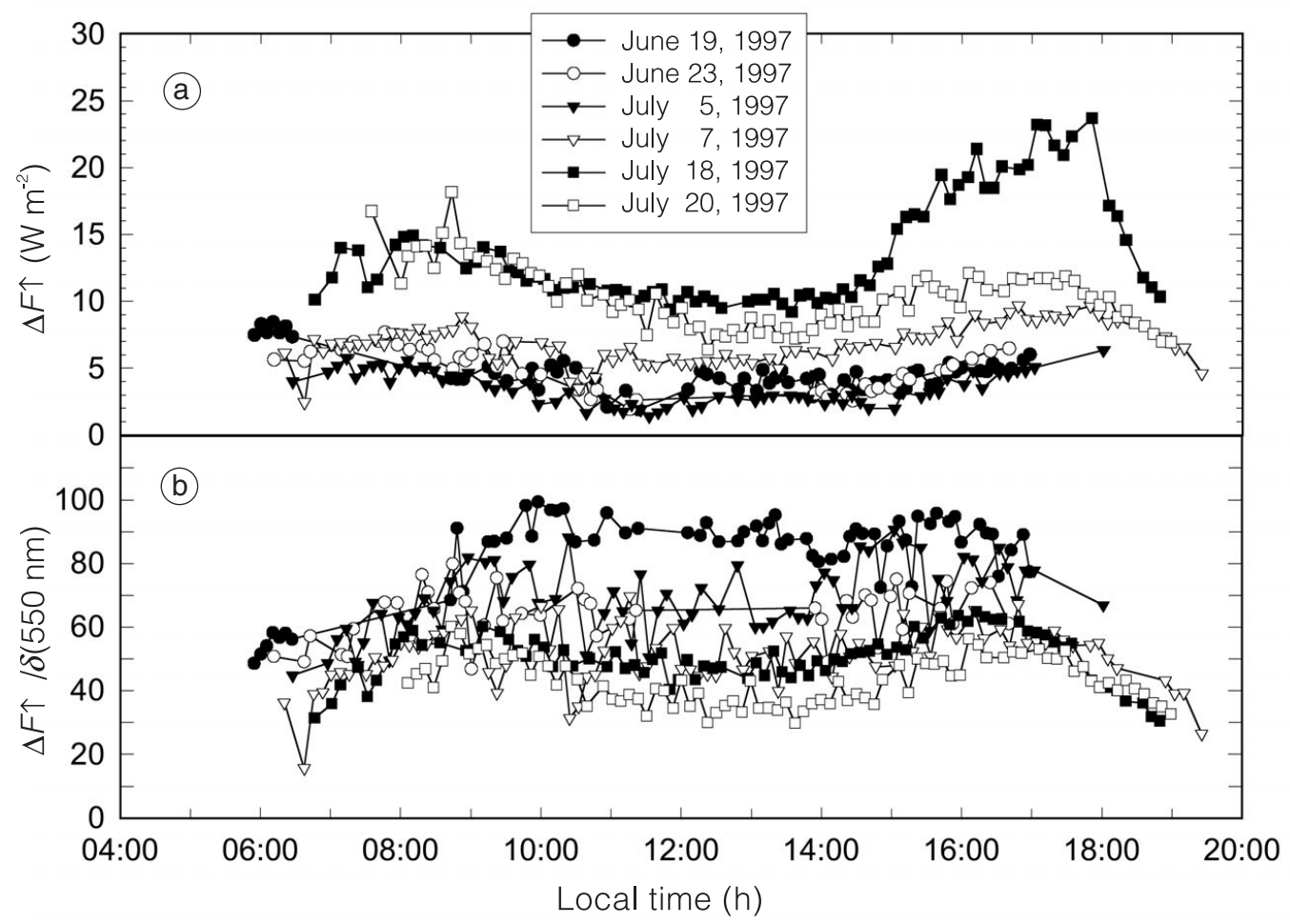

Fig. 4a,b. a) Time-patterns of the change $\Delta F \uparrow$ in the upwelling solar radiation flux at the top of the atmosphere, determined for the six selected days considered in fig. 3a,b. b) Time-patterns of change $\Delta F \uparrow / \delta(550 \mathrm{~nm})$ per unit variation of $\mathrm{AOD}$ at the mean visible wavelength, determined for the same six days.

of $\omega$ varying mainly between 0.80 and 0.85 were found together with values of AOD lower than 0.20 . Values of $\Delta F \uparrow$ mostly lower than $5 \mathrm{Wm}^{-2}$ were obtained on July 19, 1997, in the prevailing presence of marine aerosols, presumably as a result of the very low values of AOD measured on that day, in spite of the values of $\omega$ all higher than 0.94 .

Because of the above assumptions of fixed values of $n$ and $k$ during the same day, it is reasonable to bear in mind that the present estimates of $\Delta F \uparrow$ are affected by errors due to the use of both aerosol size-distribution curves and single scattering albedo characteristics different from the real conditions. Calculations similar to those perfomed in the previous section for determining parameter $\omega$ as a function of $n$ and $k$ indicate that $\Delta F \uparrow$ can vary by no more than $\pm 1.0 \%$ on July 5 for $n$ changing from 1.47 to $1.47 \pm 0.02$, and by no more than $\pm 2.0 \%$ on July 7 and July 20 for $n$ varying from 1.50 to $1.50 \pm 0.02$. On the other hand, using fixed values of $n$ on the three days together with values of $k$ modified step-by-step,
$\Delta F \uparrow$ turned out to change by about $\pm 15 \%$ on July 5 for values of $k=0.0067 \pm 0.0033$, and by percentages varying between $\pm 35 \%$ and $\pm 50 \%$ on the other two days for values of $k=0.0138 \pm$ \pm 0.0069 . These results and other supplementary calculations made for the other measurement days allow us to estimate that the use of our procedure produces on average overall relative errors in $\Delta F \uparrow$ ranging between $\pm 15 \%$ for values of $\delta(550 \mathrm{~nm})$ equal to about 0.1 , and $\pm 30 \%$ for values of $\delta(550 \mathrm{~nm})$ equal to about 0.2 .

Based on the comparison of the daily timepatterns of $\Delta F \uparrow$ with those of $\delta(550 \mathrm{~nm})$ shown in fig. $3 \mathrm{a}$, the above results clearly indicate that more marked values of $\Delta F \uparrow$ are in general obtained in cases where AOD assumes relatively high values at the visible wavelengths. To test this statement, at each measurement time of the six days we evaluated the ratios $\Delta F \uparrow / \delta(550$ $\mathrm{nm}$ ), obtaining realistic estimates of the change $\Delta F \uparrow$ per unit AOD in the visible range. The results are given in fig. 4b, which shows values of this ratio mostly higher than $80 \mathrm{Wm}^{-2}$ in the 
middle part of June 19, 1997, in the presence of pure marine aerosols, values ranging mainly between 50 and $80 \mathrm{Wm}^{-2}$ on the days with mixed aerosols and between 20 and $60 \mathrm{Wm}^{-2}$ on the two days presenting mainly continental (polluted) particles. These findings indicate that, at parity of $A O D$, marine aerosols cause the most intense changes of $F \uparrow$, since they produce very high single scattering albedo features, while continental particles containing particulate matter of anthropic origins are expected to produce less pronounced effects, which are lower by more than $50 \%$ in the most polluted cases. This demonstrates that the composition of particulate matter and the related microphysical and radiative properties (represented on the whole by the single scattering albedo of columnar aerosols) are of basic importance in determining the intensity of the aerosol effects on the upwelling solar radiation flux over oceanic areas.

\section{Discussion of the results and conclusions}

The change $\Delta F \uparrow$ represents the instantaneous radiative effect caused at the top of the atmosphere by aerosols suspended within the atmospheric vertical column of unit cross section. The present analysis provided results which point out that the variations $\Delta F \uparrow$ caused by aerosols in the radiation balance of the surface-atmosphere system can be realistically interpreted in terms of the aerosol optical depth and the single scattering albedo of the columnar particle polydispersion, the surface albedo being the third most important parameter to be taken into account in similar studies. However, we have assumed in the present study a constant surface albedo in all the examined cases, representing it through features typical of a clear water surface. In order to get a measure of the daily mean effect produced by airborne aerosols on the radiative budget of the surfaceatmosphere system, we integrated the daily timepatterns of $\Delta F \uparrow$ over the $24 \mathrm{~h}$ period. In doing so, we calculated the local times of sunrise and sunset on the six days and assumed that $\Delta F \uparrow$ is null at the initial and final time of each diurnal period, increasing linearly with time during the early morning and decreasing linearly after the last sun-radiometric measurement taken in the late afternoon. The integrals of $\Delta F \uparrow$ in time were then divided by $24 \mathrm{~h}$ to obtain the estimates of the 24-h average change $\Delta F \uparrow$ on the six days. They are plotted in fig. 5 as a function of the daily mean values of $\delta(550 \mathrm{~nm})$, as calculated from the time-patterns of this quantity shown in fig. $3 \mathrm{a}$. The results are also compared in fig. 5 with the average relationship curves obtained from those calculated by Russell et al. (1999b) on two days of the TARFOX experiment for three different values of the daily mean single scattering albedo $\varpi$ of aerosols, i.e.:

i) $\bar{\sigma}=1$ for totally scattering aerosols;

ii) $\varpi=0.935$ for marine aerosols presenting radiative properties similar to those observed by us on June 19, 1997, and

iii) $\varpi=0.86$ for mixed aerosol polydispersions containing a prevailing fraction of maritime particulate matter and less important percentages of continental origins, similar to those observed by us on June 23, July 5 and July 18, 1997.

The comparison shows that a substantial agreement exists between our evaluations and those of Russell et al. (1999b), although the present daily average estimates of $\Delta F \uparrow$ turn out to be overestimated with respect to those of the TARFOX measurements, by no more than $15 \%$ for values of $\delta(550 \mathrm{~nm})>0.15$ and by percentages varying between $8 \%$ and $62 \%$ in the other four cases. Such discrepancies can be in part explained by the different radiative properties of the airborne aerosols observed during the two experiments and in part by the irregular features of the AOD time-patterns. However, our results indicate that relationship curves like those proposed by Russell et al. (1999b), but with higher slope coefficients in the range $\delta(550 \mathrm{~nm})<0.15$, could provide reliable evaluations of the 24-h average change $\Delta F \uparrow$ for aerosol radiative characteristics more similar to those of the CLEARCOLUMN campaign.

The present evaluations of $\Delta F \uparrow$ have been obtained for low surface albedo conditions and a large variety of AOD values, columnar aerosol size-distribution curves and particulate radiative properties. The change produced by aerosol particles in the upwelling flux $F \uparrow$ is the result of highly complex radiative transfer processes occurring in the atmosphere, which mainly arise from scattering and absorption 


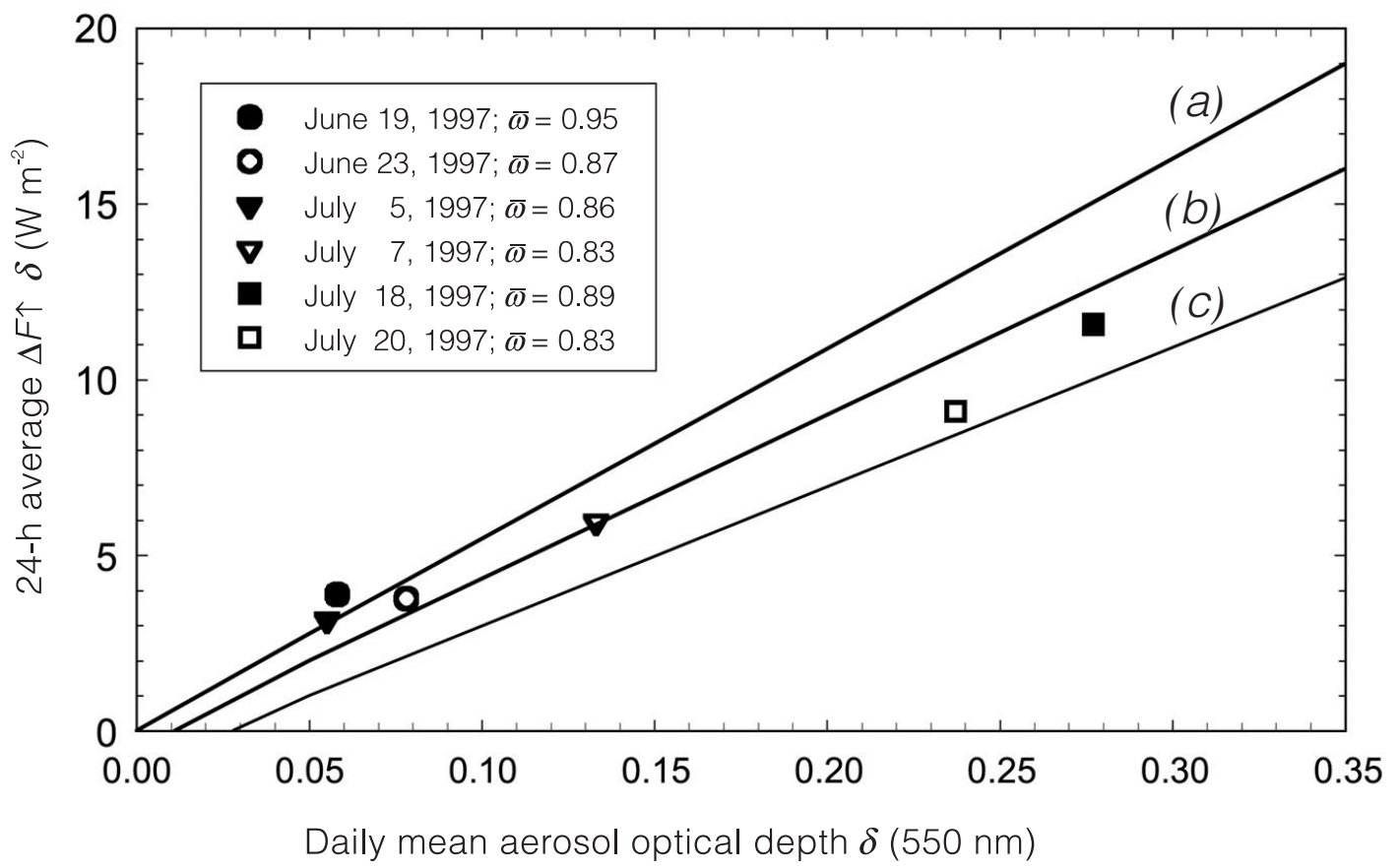

Fig. 5. Estimates of the 24-h average flux change $\Delta F \uparrow$ determined on the six selected days as a function of the daily mean aerosol optical depth $\delta(550 \mathrm{~nm})$ and for different daily average values of the columnar aerosol single scattering albedo $\varpi$. The results are compared with the relationship curves determined by Russell et al. (1999b) during the TARFOX experiment for three different values of $\varpi$ : (a) $\varpi=1.00 ;(b) \varpi=0.935$, and $(c) \varpi=0.86$.

caused by aerosols. The results show that the intensity of these processes over a calm oceanic region substantially depends on the two physical quantities AOD and $\omega$, which implicitly contain a large information set on the various microphysical and radiative parameters, such as the columnar total particle number, the shapeparameters of the particle size-distribution and the complex refractive index. The diagram in fig. 5 presenting average relationship curves obtained from the TARFOX results (Russell et al., 1999b) constitutes a useful tool for deriving reliable estimates of the 24-h average values of $\Delta F \uparrow$ in oceanic regions as a function of aerosol optical depth $\delta(550 \mathrm{~nm})$ and single scattering albedo $\omega$, both quantities being determined by combining sun-photometric measurements of direct solar irradiance with sky-brightness measurements taken in the almucantar at different angular distances from the Sun. Therefore, we can conclude that the solar radiation flux changes caused by aerosols in planetary regions presenting low surface albedo features are expected to induce cooling effects, whose entity is proportional to AOD with proportionality coefficients increasing with the aerosol single scattering albedo.

\section{REFERENCES}

Anderson, G.P., S.A. Clough, F.X. Kneizys, J.H. Chetwynd and E.P. Shettle (1986): AFGL atmospheric constituent profiles $(0-120 \mathrm{~km})$, Air Force Geophysics Laboratory (L.G. Hanscom Field, Massachusetts), Environ. Res. Papers, n. 954, AFGLTR-86-0110, pp. 43.

ÅngSTRÖM, A. (1964): The parameters of atmospheric turbidity, Tellus, 16, 64-75.

BAtes, T.S., B.J. Huebert, J.L. Gras, F.B. GrifFithS and P.A. DURKEE (1998): International Global Atmospheric Chemistry (IGAC) project's 1st Aerosol Characterization Experiment (ACE 1) overview, J. Geophys. Res., 103, $16,297-16,318$.

Charlson, R.J., J. Langner, H. Rodhe, C.B. LeOvy and S.G. WARREN (1991): Perturbation of the northern hemisphere radiative balance by backscattering from anthropogenic sulfate aerosols, Tellus, 43, 152-163.

CuRCIO, J.A. (1961): Evaluation of atmospheric aerosol particle size distribution from scattering measurements in the visible and infrared, J. Opt. Soc. Amer, 51, 548-551. 
DEIRMENDJIAN, D. (1969): Electromagnetic Scattering on Spherical Polydispersions (American Elsevier Publ. Co., Inc., New York.), pp. 56-142.

HÄNEL, G., W. AdAm, U. BundKe, L. Komguem and U. LEITERER (1999): Optical properties of boundary layer particles, columnar absorption and direct radiative forcing by particles in the solar spectral region, $J$. Aerosol Sci., 30, Suppl. 1, S171-S172.

Huebert, B.J., A. PsZENNY and B. BlomQuist (1996): The ASTEX/MAGE experiment, J. Geophys. Res., 101, 4319-4329.

JAYRAMAN, A., D. LUBIN, S. RAMACHANDRAN, V. RAMANATHAN, E. WOODBRIDGE, W. COLlins and K.S. ZALPURI (1998): Direct observations of aerosol radiative forcing over the tropical Indian Ocean during the JanFeb 1996 pre-INDOEX cruise, J. Geophys. Res., 103, $13,827-13,836$.

KING, M.D. (1982): Sensitivity of constrained linear inversions to the selection of the Lagrange multiplier, J. Atmos. Sci., 39, 1356-1369.

LANGner, J. and H. Rodhe (1991): A global threedimensional model of the global sulfur cycle, J. Atmos. Chem., 13, 255-263.

PAltridge, G.W. and C.M.R. Platt (1976): Radiative Processes in Meteorology and Climatology (Elsevier Sci. Pubbl. Co., Amsterdam), pp. 234-241.

QUENZEL, H. (1970): Determination of size distribution of atmospheric aerosol particles from spectral solar radiation measurements, J. Geophys. Res., 75, 2915-2921.

RAES, F., T. BATES, F. MCGOVERn and M. VAN LIEDEKERKE (2000): The 2nd Aerosol Characterization Experiment (ACE-2): general overview and main results, Tellus $B$, 52, 111-125.

Russell, P.B. and J. HeintzenBerg (2000): An overview of the ACE 2 clear sky column closure experiment (CLEARCOLUMN ), Tellus B, 52, 463-483.

Russell, P.B., P.V. HoBbS and L.L. STOWE (1999a): Aerosol properties and radiative effects in the United States East Coast haze plume: an overview of the Tropospheric Aerosol Radiative Forcing Observational Experiment (TARFOX), J. Geophys. Res., 104, 2213-2222.

Russell, P.B., J.M. Livingston, P. Hignett, S. Kinne, J. WONG, A. ChIEN, R. BergStrom, P.A. DURKEE and P.V. HoBBS (1999b): Aerosol-induced radiative flux changes off the United States mid-Atlantic coast: comparison of values calculated from sunphotometer and in situ with those measured by airborne pyranometer, J. Geophys. Res., 104, 2289-2307.

Tomasi, C., E. CAROLI and V. Vitale (1983): Study of the relationship between Ångström's wavelength exponent and Junge particle size distribution exponent, J. Appl. Meteorol., 22 (10), 1707-1716.

TOMASI, C., V. VITALE, A. CACCIARI and E. CARBONI (1998): Multiwavelength sun-photometer measurements of background aerosol optical depth at the Schneefernerhaus Observatory $(2665 \mathrm{~m})$ during the RAD-I-CAL 96 (ACE-2) intercomparison campaign, in Proceedings of the 25th International Conference Alpine Meteorology, 101-104.

Tomasi, C., V. Vitale, A. LuPI, A. CaCciari and S. Marani (1999): Use of multiwavelength sun-radiometers for precise ground-based measurements of the aerosol optical thickness, in IGARSS 1999 Proceedings, vol.I, 354-358.

TOMASI, C., S. MARAni, V. Vitale, F. WAGNER, A. CACCIARI and A. LUPI (2000): Precipitable water evaluations from infrared sun-photometric measurements analyzed using the atmospheric hygrometry technique, Tellus $B$, 52, 734-749.

Vermote, E., D. Tanré, J.L. DeuZÉ, M. Herman and J.J. MORCRETTE (1997): Second Simulation of the Satellite Signal in the Solar Spectrum (6S): user's guide, Technical Report Version 2, Department of Geography, University of Maryland, c/o NASA-Goddard Space Flight Cente Code 923, Greenbelt, MD 20771, USA, pp. 218.

Vitale, V., C. Tomasi, W. von Hoyningen-Huene, U. Bonafé, S. MARANi, A. Lupi, A. CACCIARI and P. RUGGERI (2000a): Spectral measurements of aerosol particle extinction in the 0.4-3.7 $\mu \mathrm{m}$ wavelength range, performed at Sagres with the IR-RAD sun-radiometer, Tellus B, 52, 716-733.

Vitale, V., C. Tomasi, A. Lupi, A. Cacciari and S. MARANI (2000b): Retrieval of columnar aerosol size distributions and radiative-forcing evaluations from the sun-photometric measurements taken during the CLEARCOLUMN (ACE-2) experiment, Atmos. Environ., 34, 5095-5105.

VON HOYNINGEN-HUENE, W., K. WENZEL and S. SCHIENBEIN (1999): Radiative properties of desert dust and its effect on radiative balance, J. Aerosol Sci., 30, 489-502. 